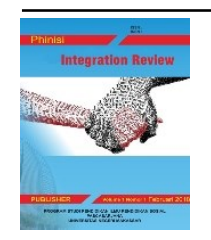

Phinisi Integration Review

Vol. 4, No.1, Februari 2021 Hal 24-31

Website: http://ojs.unm.ac.id/pir

p-ISSN: 2614-2325 dan e-ISSN: 2614-2317

DOI: https://doi.org/10.26858/pir.v4i1.19217

\title{
Pappasang To Riolo: Belajar dari Petuah Leluhur dalam Membentuk Siswa Berkarakter
}

\author{
Ahmad Subair ${ }^{1}$ \\ ${ }^{1}$ Pendidikan Sejarah, Universitas Negeri Makassar, Indonesia \\ Email: ahmadsubair@unm.ac.id
}

\begin{abstract}
Abstrak. Tulisan ini mencoba melihat fenomena nir-adab yang terjadi pada siswa saat ini, dan mencari jalan keluarnya melalui serangkaian peristiwa di masa lalu dengan nilai kearifan lokal di masa lalu. Ada dua hal (lebih tepatnya tawaran) yang ingin disampaikan pada tulisan ini dalam memecahkan masalah tersebut. Pertama, penjelasan tentang nilai kearifan lokal yang terkandung pappasang to riolo, kedua mengisahkan suri tauladan toriolo (leluhur). Kedua hal tersebut di-integrasikan ke dalam materi sejarah dan disampaikan kepada peserta didik agar muaranya tercipta siswa yang berkarakter. Tulisan ini menggunakan metode penelitian kuliatatif dengan pendekatan antropologi-historis dalam melihat karakter (nilai) siswa yang mengalami degradasai moral. Hasil Penelitian ini adalah model baru pendekatan pendidikan karakter dengan menggunakan budaya sebagai role modelnya.
\end{abstract}

Kata kunci : Pappaseng to Riolo, Petuah Leluhur, Pendidikan Karakter.

\begin{abstract}
This paper tries to look at the irreverent phenomena that occur in students today, and to find a way out through a series of events in the past with the value of local wisdom in the past. There are two things (more precisely an offer) to be conveyed in this paper in solving this problem. First, an explanation of the value of local wisdom contained in pappasang to riolo, the second tells about the exemplary suri to-riolo (ancestors). These two things are integrated into the historical material and conveyed to students so that students with character can be created. This paper uses a qualitative research method with an anthropological-historical approach in seeing the character (value) of students who experience moral degradation. The results of this study are a new model of character education approach using culture as a role model.
\end{abstract}

Keywords: Pappaseng to Riolo; Ancestral Advice; Character Education.

c) (7) (8) Ini adalah artikel dengan akses terbuka dibawah licenci CC BY-NC-4.0

(https://creativecommons.org/licenses/by-nc/4.0/ ).

\section{PENDAHULUAN}

Prilaku kekerasan terjadi disekolah, menggambarkan degradasi moral. "Tak Terima Ditegur, 3 Pelajar SMA di Kupang Aniaya Guru" Tiga pelajar SMA Negeri 1 Fatuleu, Kabupaten Kupang, NTT, ditanngkap aparat kepolisian lantaran menganiaya gurunya sendiri, YM (45 tahu) (Liputan6.com, 2020). "Ditegur Karena Merokok di Lingkungan Sekolah, Siswa SMK
Aniaya Guru" Aparat porlesta Manado telah menahan FL (16), seorang siswa yang melakukan penganiyaan berupa penikaman terhadap AP (54), guru salah satu SMK di Manado pada Senin, 21 Oktober 2019 (Liputan6.com, 2019).

Setidaknya dua kutipan berita daring di atas memberikan gambaran kepada kita tentang kasus degradasi moral yang dimiliki oleh siswa. Menagapa penulis menyatakan hal demikian? Karena logika-nya tidak ada siswa yang 
menganiaya gurunya lantaran seorang guru menegur siswa-nya. Hal tersebut juga mencerminkan bahwa adab baik dan tingkah laku seorang siswa terhadap guru saat ini sudah jarang ditemukan. Hal tersebut kadang disaksikan oleh penulis ketika sedang berkunjung dalam lingkungan sekolah, beberapa kali penulis menjumpai atau mendengar siswa yang mengeluarkan umpatan-umpatan kepada guru mereka. Walaupun, kasus tersebut tidak sertamerta menjustifikasi bahwa semua siswa di negeri ini memiliki perilaku banal, masih terdapat pula siswa-siswi yang memiliki perilaku yang sopan, beradab, dan bertutur kata halus.

Salah satu upaya dalam mengembalikan siswa berperilaku banal agar kembali ke jalan yang benar adalah menguatkan pendidikan karakter, semisal menanamkan nilainilai luhur, norma kesopanan, adab, etika, kepada peserta didik. Tentunya, materi pendidikan karakter banyak tertuang dalam mata pelajaran PKN dan Pendidikan Agama \& Budi Pekerti. Walaupun demikian, kita tidak bisa berkecil hati bahwa menanamkan karakter kepada peserta didik haruslah menjadi seorang pengajar PKN atau Pendidikan Agama \& Budi Pekerti, menjadi seorang pengajar di luar bidang tersebut juga dituntut untuk mampu menamankan nilai luhur kepada peserta didik, karena sesungguhnya esensi dari pendidikan itu adalah memanusiakan manusia.

Di dalam menanamkan pendidikan karakter kepada peserta didik, materi sejarah juga memainkan peranan penting, yakni mencari hikmah dari serangkaian penjelasan atas peristiwa-peristiwa masa lalu (red: materi sejarah), dari proses itu kita dapat menceritkan kepada siswa mengenai hikmah (atau nilai luhur) yang dapat dipetik dari proses "belajar dari sejarah" tersebut. Tarulah sebuah contoh, Perang Makassar.(Mappangara, 2016) Konflik yang melibatkan Kerajaan Gowa dengan Kerajaan Bone (di Bantu VOC) yang berlangsung sangat lama tersebut menimbulkan berbagai kerugian oleh kedua belah pihak. Kekalahan Kerajaan gowa menandai masuk dan berkuasanya kolonialisme di Sulawesi-selatan. Kita tahu bersama bahwa selama pendudukan Belanda di Sulawesi-Selatan telah melahirkan kesengsaraan yang berkepanjangan bagi pribumi (Poelinggomang, 2016).

Sebagai seorang pendidik, kita dapat memberikan hikmah atas pembelajaran dari peristiwa tersebut dengan berujar kepada peserta didik "jangan jadi orang yang mau dipecah belah, jangan mudah bersilih paham dengan orang lain apatah lagi orang-orang terdekat, dan nantinya jadilah pribadi yang baik dan selalu hormat kepada orang tua".

Diharapkan peserta didik mampu memetik hikmah tersebut dan dijadikan satu pedoman hidup yang beriringan dengan falsafah Pancasila dan nilai-nilai yang terkandung dalam ajaran agama sehingga esensi dari pendidikan( yakni memanusiakan manusia) dapat tercapai dan menciptakan peserta didik tidak hanya pandai namun juga beradab.

Memberikan hikmah dapat dilakukan dengan mengisahkan kembali kisah leluhur pada skop lokal dalam hal ini sejarah lokal Sulawesi Selatan. Hal tersebut dianggap penting karena mengingat peserta didik akan lebih menaruh perhatian lebih sekiranya menyinggung tentang muasal dari leluhurnya.

Berbicara mengenai Sulawesi Selatan, maka ingatan kolektif masyarakatnya akan bertumpu pada romantisme kebesaran Kerajaan Gowa-Tallo dengan Sultan Hasanuddin sebagai episentrum dalam kisah tersebut (Limpo, 1995). Padahal sejarah tentang daerah Sulawesi Selatan tidak hanya bertumpu pada kisah kepahlawanan Sultan Hasanuddin, banyak tokoh yang bisa dijadikan patron bagi generasi muda zaman sekarang.

Kisah-kisah tentang suri tauladan ketokohan sejarah Sulawesi Selatan dapat dilacak dari lontaraq (seperti Lontaraq Patturiolonna to Goa ) (Wolhoff, n.d.) atau sinriliq (seperti : Sinriliq I Tolo' Daeng Magassing ) maupun paupau ri kadong (Agre, 1992). Kisah tersebut diwariskan secara turun temurun, dari generasi ke generasi. Kisah yang dituturkan itulah kadang juga disebut Papaseng to Riolota atau Wasiat/Petua Orang-Orang Dahulu (Abdul Rahmam Rahim, 1984).

Ada dua hal yang ingin diungkapkan penulis mengenai pentingnya makalah ini. Pertama, mencari solusi atas kegusaran pemakalah atas degradasi moral siswa belakangan ini. Secara jujur pemakalah ingin menyampaikan bahwa siswa-siswa yang dihadapi memiliki perilaku yang banal, yakni menampilkan tindak-tanduk nir-adab terhadap guru. Kedua, makalah ini menjadi bagian kecil dari upaya melestarikan warisan masa lalu, terutama petuah-petuah leluhur yang kini jarang lagi terdengar, sehingga masyarakat mampu mengenali kembali siapa dirinya, siapa leluhurnya, serta bagaimana latar belakang historis dan budayanya. 
Sesarinya, muara dari makalah ini menghasilkan suatu dialektika ilmu pengetahuan serta mencari solusi atas permasalahan yang dihadapi terutama permasalahan nir-adab siswa kepada gurunya dan secara bersama-sama mencari solusi terbaik atas masalah yang dihadapi seorang pengajar.

Sepanjang bacaan peneliti, belum ada sebuah penelitian yang membahas masalah yang sama diajukan oleh pemakalah. Namun terdapat penelitian yang dapat dijadikan rujukan dalam mengembangkan karya tulis ilmiah ini, Pertama adalah karya A. Rahman Rahim, (1984) berjudul Nilai-Nilai Utama Kebudayaan Bugis dan karya M. Arif Mattalitti, (1986) berjudul Pappaseng to Riolota : Wasiat Orang Dahulu. Dua karya sebelumnya inilah yang membantu pemakalah dalam mencari benang merah atas masalah yang dialami saat ini dengan jawaban atas masalah tersebut dilihat dari

\section{METODE}

Tulisan ini menggunakan pendekatan kualitatif dengan jenis Penelitian Pendidikan Sejarah. Penelitian ini adalah bentuk penelitian Kepustakaan. Namun, tidak dikategorikan sebagai Kajian Kepustakaan. Lebih tepatnya pengembangan model pendidikan dan pengajaran sejarah. Karena point of view bukan terletak pada konten yang akan diajarkan, namun penarikan nilai yang akan diinternalisasikan oleh siswa.

Terdapat dua hal yang menjadi instrumen penting dari penelitian ini yang pertama adalah critical pedagogy dan kedua kompetensi pemahaman nilai nilai di balik peristiwa sejarah.

Hal yang sama pernah di tulis oleh (Ahmad, 2014) yaitu kendala guru dalam mengintrenalisasi pendidikan karakter pada mata pelajaran sejarah. Namun, dalam sisi pendekatan, penelitian ini berbeda. Penelitian ini poinya pada cara menjadikan sejarah sebagai pendidikan nilai sedang, Ahmad mendeskripsikan kendala pendidikan nilai (karakter).

\section{HASIL DAN PEMBAHASAN}

\section{Petuah-Petuah dari Leluhur}

Papilajarang to Riolo: Belajar dari Masa Lalu melalui Narasi Pappaseng to Riolo. Sipakatau, Sipakainga, Sipakalebbi tiga untaian kata yang sudah sangat familiar di telinga masyarakat Sulawesi-Selatan, kurang lebih berarti saling menghormati, saling mengingatkan, dan saling
menghargai(Perlas, 2005). Inti tiga untaian kata tersebut itulah disebut dengan pappaseng atau petuah, petuah tersebut tidak hanya dilafalkan melainkan pula diamalkan, termasuk di dunia pendidikan.

Sebagaimana esensi dari pendidikan (yakni memanusiakan manusia) mengajarkan pappaseng kepada peserta didik dipandang perlu dalam menguatkan karakter peserta didik. Di dalam bagian ini akan diungkapkan beberapa pappaseng to riolo yang selaras dengan nilainilai utama Bugis-Makassar yang harus dimiliki oleh peserta didik yakni (1) lempu'/ lambusu' (kejujuran); (2) accal caradde' (kecerdasan/kecendekiaan).

Rahman Rahim (1984:144-146) dalam bukunya berjudul Nilai-Nilai Utama Kebudayaan Bugis mengemukakan bahwa salah satu nilai terpenting yang kiranya wajib dimiliki masyarakat adalah kejujuran. Jujur dalam bahasa Bugis berarti lempu' dalam Bahasa Makassar disebut lambusu' keduanya memiliki arti yang sama yakni, lurus. Lempu' atau lambusu' dalam berbagai konteks adakalanya berarti ikhlas, baik, adil) sehingga memiliki lawan kata yakni culas, khianat, curang, dusta.

Nilai kejujuran ini selaras dengan papaseng to riolo yang berbunyi Aja muploi olona tauwwe, yang berarti "janganlah memotong jalan-nya seseorang" hal ini berarti jangan mengambil hak orang lain (Rahim, 1984). Lebih lanjut, dalam ungkapan papaseng to riolo disebutkan pula bahwa "Eppai asalewangng riwatakkalee naompo alebbireng ianaritu : Alempureng; Asuleksanangeng; Assawolong polongeng; Assabarakeng"'(Rahim, 1984) yang berarti Ada empat ketentuan pada diri kita yang menimbulkan keutamaan: Kejujuran; Kebijaksanaan; Kerukunan; Kesabaran. Apabila dilihat maka nilai kejujuran merupakan salah satu nilai utama yang harus dimiliki oleh tiap-tiap pribadi seoeorang.

Oleh nya itu sebagai seorang pengajar dalam membentuk karakter siswa yang baik nan sopan kiranya menanamkan betapa pentingnya nilai kejujuran. Penyampaian amanat (dari guru ke peserta didik) tentang pentingnya kejujuran mengingatkan penulis pada kisah Karaeng Matoawaya (Poelinggomang \& Mappangara, 2004) yang menasehati Karaeng Pattingngalloang bahwa takuti [segani] lah orang jujur (Rahim, 2011) pernyataan ini membuktikan bahwa betapa dahulu di masa kerajaan, kejujuran itu begitu mulia, sekelas Raja Tallo memberikan petuah kepada puteranya 
bahwa yang ditakuti bukanlah kekuatan milter yang besar, melainkan pribadi yang jujur. Kata takut di sini bisa diartikan sebagai "segan.

Selain nilai kejujuran sebagaimana yang telah diungkapkan sebelumnya, peserta didik tentunya harus mampu memiliki kecerdasan. Kecerdasan dalam bahasa Makassar disebut caradde sedang dalam bahasa Bugis disebut acca' dua kata ini bisa diartikan sebagai cendekia, cendekia sangat dekat dengan kearifan.(Rahim, 1984) Dengan demikian peserta didik diharapkan memiliki sifat acca karena dengan acca ini akan menumbuhkan karakter yang arif.

Di dalam konsep kecendekian terkandung nilai kejujuran, kebenaran, kepatutan, keihkhlasan, dan penyiasatan atau penelitian. Tociung menyebutkan bahwa cendekia ialah mencintai perbuatan dan kata yang benar, dan berhati-hati melaksanakan segala sesuatu. Pappaseng Bugis yang menyatakan Pura babbara sompekku, pura tangkisi gollikku, ulebbirenni telllengngE na towaliE (Mattalitti, 1986:27) memiliki makna yang sama, yakni melaksanakan segala sesuatu dengan kehatihatian atau dengan pertimbangan matang. Peserta didik yang memiliki sifat acca akan mengambil tindakan dengan pertimbangan yang matang.

Kasus yang telah diungkapkan dalam latar belakang sebelumnya membuktikan bahwa siswa tersebut tidak memiliki sifat acca, karena mengambil tindakan tanpa berpikir dengan matang. Di dalam lontara atau historiografi tradsional Sulawesi Selatan, mereka yang ditokohkan sebagai to-acca ialah Tociung, Kajaolalidong, La Pagala Nene' Mallomo, Karaeng Pattingngalloang, Ammanagappa dan banyak lainnya (Tobing, 1977)

\section{Belajar dari Pengalaman Lakon Sejarah Sulawesi Selatan}

Pada bagian ini akan disajikan profil singkat dari cendekiawan Bugis-Makassar di masa lalu, penyajian ini dipandang penting agar pembaca (terutama yang dibidikan kepada peserta didik) dapat mengambil suatu inspirasi dan ketauladanan dari tokoh sejarah tersebut, karena bagaimanapun belajar sejarah tidak hanya merangsang pengetahuan (kemampuan kognitif) para peserta didik, belajar sejarah juga memberikan kepada peserta didik nilai ketauladanan dari pelaku sejarah sebagaimana salah satu guna belajar sejarah yakni inspiratif (Tamburaka, 1999: 5-9).

\section{Nilai Kejujuran Lamunassa \\ Toakkarangeng dan Nene Mallomo}

Sebagaimana telah diungkapkan pada pembahasan sebelumnya, salah satu nilai utama yang kiranya ditanamkan kepada peserta didik adalah kejujuran, salah satu kisah kejujuran yang dapat diteladani oleh peserta didik adalah kisah Lamunassa Toakkarangeng (Poelinggomang \& Mappangara, 2004). Disebutkan bahwa Kerajaan Soppeng kala itu ditimpa bencana, dan dalam kepercayaan setempat bencana datang dikarenakan kelalaian manusia dalam menjalankan pangadareng (hukum adat) atau seseorang telah berbuat zalim. Lamunassa Toakkarang selaku raja mencari jalan keluar dari masalah tersebut, hingga pada satu titik ia menemukan dirinya telah berbuat zalim. Di depan khayalak ramai ia menjatuhkan hukuman atas dirinya sendiri karena perkara memungut barang (beberapa sumber menyebutkan alat bajak) di sawah lalu menyuruh seseorang untuk menyimpannya ( Rahim, 2011).

Apabila ditelisk secara seksama, nilai kejujuran yang terkandung dalam kisah Lamunassa Toakkarangeng terletak pada sikap kesatrianya dalam mengakui kesalahan yang dilakukannya, hal ini membuktikan bahwa betapa pentingnya nilai kejujuran bagi seorang pemimpin. Hal ini senada dengan kisah La Pagala Nene' Mallomo seorang hakim di Sidenreng yang menjatuhkan hukuman mati terhadap anaknya sendiri dikarenakan perkara ketidak jujuran sang anak yakni mengambil salaga' (alat yang dipakai membajak)( Rahim, 2011:150). Pada kesempatan ini dapat dilihat bahwa setiap perbuatan yang tidak jujur akan diganjar hukuman, sebagaimana yang ditimpahkan Nene Mallomo kepada anaknya. Di satu sisi lain kita dapat melihat bahwa betapa di masa lalu hukum ditegakkan tanpa pandang bulu, sebagaimana ungkapan Nene' Mallomo ketika memutus perkara tersebut, yakni Iare Ade’ Temmakkeana, Temmakke-eppo, yang namanya hukum tidak mengenal anak dan cucu (Rahim, 2011: 150).

\section{Nilai Kecendekiawanan Karaeng Pattingngalloang}

"Bola dunia itu, perusahaan Hindia

Timur mengirimkannkan ke istana Pattingngalloang yang agung, yang otaknya menyelidik kemana-mana dan menganggap dunia seutuhnya terlalu kecil, kami berharap tongkat kekuasaannya memanjang dan mencapai kutub yang satu dan yang lainnya. Agar keuzuran 
waktu hanya melapukkan tembaga itu bukan persahabatan kita."

Joost van den Vondel-(Lombard, 2005)

Apa yang tertuang di atas adalah sepenggal syair yang diutarakan oleh seorang misionaris asal Belanda bernama Joost van den Vondel kepada Karaeng Pattingngalloang, urita tersebut dapat dijumpai dalam salah satu buku Denys Lombard (Lombard, 2005) yang berjudul Nusa Jawa Silang Budaya. Di dalam buku tersebut, Lombard mengemukakan bahwa Karaeng Pattingngalloang pada satu masa (22 Juli 1664) pernah melakukan transaksi dengan salah seorang pelaut Belanda, mangkubumi Kerajaan Makassar tersebut memberikan kayu cendana seharga 660 real disertai dengan daftar pesanan barang-yang kapten kapal tersebut menyebut pesanan Pattingngalloang adalah pesanan raritten atau barang langka-dengan rincian sebagai berikut: (1) Dua bola dunia Atlas, yang besar berukuran 157-160 Inci terbuat dari tembaga, gunanya menentukan letak arah kutub utara dan selatan; (2) Sebuah Peta Dunia yang berukuran besar yang Berbahasa Spanyol, Portugis atau Latin; (3) Sebuah Atlas Besar dan penjelasan yang terpeinci yang berbahasa Spanyol, Portugis, atau Latin; (4) Dua buah Teropong berukuran besar dan berkualitas terbaik - lengkap dengan Surya Canta yang besar dan berkualitas tinggi; (5) Dua buah Prisma Segitiga yang memungkinkan untuk mendekomposisikan cahaya; (6) Tiga puluh sampai empat puluh buah tingkat baja kecil; (7) Sebuah bola dari tembaga atau baja. Sedangkan dalam catatan Fride Rhodes, Karaeng Pattingalloang menghayati Tehnical Inovation Europe, dan ia merupakan orang Asia Tenggara pertama yang menyadari pentingnya matematika guna ilmu-ilmu terapan (Aplied Science) (SAV PUSKAT, 2018).

Kecintaan Pattingngalloang terhadap buku dan ilmu pengetahuan barat ini juga dipengaruhi dengan perkembangan pengetahuan di Eropa pada Abad ke XVI dan XVII. Di dalam catatan sejarah, masa Patingalloang hidup pada paruh abad XVI hingga XVII bertepatan pada masa puncak berlangsungnya abad pencerahan di Eropa, di abad ini lahir tokoh pemikir, pembaharu, saintifis sekaliber Martin Luther, Kalfin, Kopernikus, Kepller, Galileo, dan berbagai tokoh intelektual lainnya. Dunia ilmu pengetahuan mengalami kemajuan di abad ini, karena itu tidak heran Karaeng Pattingalloang yang berada jauh di Timur ikut terpengaruh.
Kecerdasan seorang Pattingalloang sedikit banyak membantu Kesultanan Makassar dan penguasa Makassar saat itu (Sultan Malikud Said Raja Gowa ke XV) dalam menggapai masa kejayaan dan gemilangnya. Ahmad Sewang (2005) dalam bukunya berjudul Islamisasi Kerajaan Gowa Abad XVI-XVII menyebutkan bahwa Karaeng Pattingalloang sebagai mangkubhumi dari Kerajaan Gowa (Kesultanan Makassar) dikenal luas sebagai orang yang menguasai berbagai bahasa asing di antaranya Portugis, Belanda, Inggris, Spanyol, Italia, Cina, Arab, dan lain-lain. Perihal penguasaan bahasa, Alexander Rhodes, seorang Misionaris di Makassar pada tahun 1646 pernah menulis tentang kemampuan berbahasa Portugis sang Mangkhubumi Kerajaan Gowa itu (Tika, 2007).

"Karaeng Patingalloang adalah orang yang menguasai semua rahasia ilmu barat, sejarah kerajaan-kerajaan Eropa dipelajarinya, selalu memegang buku matematika yang dipelajarinya, tiap hari dan tiap malam Ia membaca buku-buku ilmu pengetahuan barat. Mendengarkan Ia berbahasa Portugis tanpa melihat orangnya, maka orang akan menyangka, bahwa orang yang berbicara itu adalah orang Portugis totok dari Lisabon. "(Limpo, 1995)

Karaeng Pattingngalloang juga dikenal menjalin persahabatan dengan raja-raja asing (penguasa Barat) serta menguasai ilmu-ilmu barat guna untuk mentransformasikan pengalaman dan pengetahuan teknik dari bangsa asing tersebut. Pengetahuan yang ditransfer adalah pengetahuan tentang peta maritim dan penyempurnaan penulisan catatan harian (lontara) dengan dilengkapi penanggalan Hijriyah dan Masehi (Sewang, 2005).

\section{Mengajarkan Pappaseng to Riolo kepada Siswa}

Sebagaimana yang telah diuraikan pada latar belakang tersebut di atas, salah satu cara untuk membentuk peserta didik berkarakter adalah menanamkan nilai-nilai kearifan lokal yang terdapat pada pappaseng to riolo maupun suri tauladan tokoh sejarah masa lalu. Kemudian timbul pertanyaan, bagaimana cara seorang guru menanamkan nilai suri tauladan terutama guru sejarah?

Sebagaimana telah diketahui bersama, dalam kurikulum 2013 terdapat dua mata pelajaran sejarah, pertama Sejarah Wajib atau lebih dikenal dengan Sejarah Indonesia, dan kedua adalah Sejarah Peminatan. Mata pelajaran yang dapat digunakan para guru/pengajar untuk 
mengintegrasikan nilai-nilai kearifan lokal yang terkandung pada pappaseng to riolo ialah materi ajar pada mata pelajaran Sejarah Peminatan, terutama pada materi di semester satu dan semester dua.

Walaupun demikian, tidak dapat dinafikan bahwa pengajar dapat pula memadukan papaseng to riolo dan nilai kearifan lokal BugisMakassar pada materi ajar di mata pelajaran
Sejarah Wajib dan Sejarah Peminatan, baik di jenjang kelas 10, 11, dan 12 .

Namun mengingat batasan dari makalah ini, maka penjelasan. pemakalah hanya terpusat pada beberapa K.D di mata pelajaran Sejarah Peminatan kelas 10 Semester 1 dan 2. Agar lebih memudahkan pembaca dalam memahami alam pemikiran penulis kiranya akan ditampilkan Program Tahunan mata pelajaran Sejarah Peminatan.

Tabel. 3.1 Kompetensi Dasar

\begin{tabular}{llc}
\hline SMT & \multicolumn{1}{c}{ Kompetensi Dasar } & \multicolumn{1}{c}{$\begin{array}{c}\text { Alokasi } \\
\text { Waktu }\end{array}$} \\
\hline 1 & $\begin{array}{l}\text { 3.3 Menganalisis keterkaitan peristiwa sejarah tentang manusia di masa lalu untuk } \\
\text { kehidupan masa kini }\end{array}$ \\
\cline { 2 - 2 } & $\begin{array}{l}\text { 4.3 Membuat tulisan tentang hasil kajian mengenai keterkaitan kehidupan masa } \\
\text { lalu untuk kehidupan masa kini }\end{array}$ \\
\hline 2 & $\begin{array}{l}\text { 3.7 Memahami langkah-langkah penelitian sejarah (heuristik, kritik/verifikasi, } \\
\text { interpretasi/eksplanasi, dan penulisan sejarah) }\end{array}$ \\
\cline { 2 - 2 } & $\begin{array}{l}\text { 4.7 Menerapkan langkah-langkah penelitian sejarah (heuristik, kritik/verifikasi, } \\
\text { interpretasi/ eksplanasi dan penulisan sejarah) dalam mempelajari sumber sejarah } \\
\text { yang ada di sekitarnya }\end{array}$ \\
\hline 3 & 3.8 Menganalisis ciri-ciri dari historiografi tradisional, kolonial, dan modern \\
\cline { 2 - 2 } & $\begin{array}{l}\text { 4.8 Menyajikan hasil kajian ciri-ciri historiografi tradisional, kolonial, dan modern } \\
\text { dalam bentuk tulisan dan/atau media lain }\end{array}$ \\
\hline
\end{tabular}

Pada bagian yang tertera di atas, guru dapat berimprovisasi mengintegrasikan materi sejarah dengan pappaseng to riolo pada bagian K.D. $\quad 3.3$ yang berbunyi "Menganalisis keterkaitan peristiwa sejarah tentang manusia di masa lalu untuk kehidupan masa kini”. Materi ini memberikan ruang untuk guru berimprovisasi dalam menanamkan nilai kejujuran atau lempu' dengan menjelaskan fenomena korupsi di kalangan pejabat di masa sekarang lalu menariknya dengan peristiwa di masa lalu. Tarulah contoh kasus tertangkap tangannya salah satu ketua partai di Indonesia yang pernah terjadi di tahun 2019.

Sebagaimana yang tercatat di pemberitaan, bahwa tertangkapnya sang ketua partai ada hubungannya dengan "jual beli jabatan" di salah satu instansi pemerintahan (Harian Fajar Makassar, 2019). Perilaku tersebut mencerminkan adanya perilaku krisis kejujuran, tidak amanah, dan perbuatan tercela lainnya. Pada bagian ini pengajar dapat mengintegrasikan nilai lempu dengan mengungkapkan kisah kejujuran dan Ketauladanan Nene Mallomo, Raja Soppeng
Lamunassa Toakkarangeng serta pappaseng to riolo yang diungkapkan Karaeng Pattingngalloang mengenai lima perkara hancurnya suatu negeri (negara) (Tika, 2007).

Dengan menyampaikan pappaseng to riolo dan nilai kearifan lokal masyarakat Sulawesi Selatan, diharapkan peserta didik mampu mengambil hikmah dan pembejalaran di dalamnya dan tercipta peserta didik yang memiliki perilaku lempu' atau jujur. Agar semakin efektif, pengajar dapat menugaskan peserta didik untuk menganalisa peristiwa dan permasalhan yang terjadi di masa kini dan mencari jawaban dari permasalhan tersebut dengan melihat kejadian di masa lalu, tentunya guru menekankan konten atau nilai kelokalan. Tentunya penugasan ini senada dengan tujuan K.D. 4.3 yang berbunyi 4.3 "Membuat tulisan tentang hasil kajian mengenai keterkaitan kehidupan masa lalu untuk kehidupan masa kini".

Improvisasi juga dapat dilakukan guru pada K.D. 3.7 yang berbunyi "Memahami langkah-langkah penelitian sejarah (Heuristik, Kritik/Verivikasi, Interpretasi/Eksplanasi, dan 
Penulisan Sejarah/Historiografi) termasuk K.D. 3.8 dan 4.8 (lihat tabel di atas). Tentunya guru akan menjelaskan secara teoritis materi tersebut, lalu memberikan penugasan kepada peserta didik untuk membuat tulisan sejarah, semisal memberikan tema "Nilai Kearifan Lokal dalam Sejarah Sulawesi Selatan". Tema tersebut akan menggiring siswa menggali nilai-nilai luhur serta menabalkan pengetahuan mereka tentang local genius $(\mathrm{Red}=$ falsafah kehidupan) yang dimiliki oleh masyarakat Sulawesi Selatan

Dengan mengabungka konten lokal (yang telah dijelaskan pemakalah pada pembahasan sebelumnya) dengan materi sejarah yang diajarkan, diharapkan menumbuhkan siswa yang berkarakter, berperilaku sopan, hormat kepada orang tua, dan adab terhadap guru. Karena bagaimanapun di dalam pappaseng to riolo disebutkan bahwa ada dua hal kelakuan manusia yang mendatangkan keburukan yakni: tau temmatepparingnggi anre gurunna dan pasalae gaukna ritomatoana.(Mattalitti, 1986:58)

\section{SIMPULAN DAN SARAN}

Dari pembahasan sebelumnya dapat disimpulkan bahwa pappaseng to riolota, nilai kearifan lokal, dan kisah ketauladanan tokoh sejarah (lokal) di masa lalu dapat dijadikan konten pembelajaran sejarah guna menciptakan siswa berkarakter, siswa yang beradab, siswa sopan, dan siswa yang hormat kepada orang tua dan adab kepada guru.

Sejarah adalah ilmu yang kerap kali dianggap membosankan oleh peserta didik. Oleh sebab itu sangat penting kiranya bagi guru untuk dapat menerjemahkan tantangan zaman dengan pendekatan nilai dan menarik sebuah mkana dari petuah leluhur dalam kondisi pengajaran yang serba terbatas.

\section{DAFTAR RUJUKAN}

Agre, R. (1992). I Tolok Daeng Magassing: Suatu Studi Transformasi Cerita Rakyat Makassar.

Ahmad, T. A. (2014). Kendala Guru dalam Internalisasi Nilai Karakter pada Pembelajaran Sejarah. Khazanah Pendidikan, 7(1).

Harian Fajar Makassar. (2019, March 17). 1 \& 11.
Limpo, S. Y. (1995). Profil Sejarah, Budaya dan Pariwisata Gowa. Cet. I.

Liputan6.com. (2019, October 23). Ditegur karena Merokok di Lingkungan Sekolah, Siswa SMK Aniaya Guru. liputan6.com. https://www.liputan6.com/regional/read/ 4092830/ditegur-karena-merokok-dilingkungan-sekolah-siswa-smk-aniayaguru

Liputan6.com. (2020, March 5). Tak Terima Ditegur, 3 Pelajar SMA di Kupang Aniaya Guru. liputan6.com. https://www.liputan6.com/regional/read/ 4194378/tak-terima-ditegur-3-pelajarsma-di-kupang-aniaya-guru

Lombard, D. (2005). Nusa Jawa Silang Budaya: Jaringan Asia. Jakarta: Gramedia.

Mappangara, S. (2016). Filosofi Arung Palakka. Ombak.

Mattalitti, M. A. (1986). Pappaseng To Riolota Wasiat Orang Dahulu. Jakarta: Departemen Pendidikan dan Kebudayaan Proyek Penerbitan Buku Sastra ....

Perlas, C. (2005). The Bugis (Manusia Bugis).

Poelinggomang, E. L. (2016). Makassar abad $X I X$. Kepustakaan Populer Gramedia.

Poelinggomang, E. L., \& Mappangara, S. (2004). Sejarah Sulawesi Selatan, Jilid 1. Ujung Pandang: Balitbangda [Badan Penelitian Dan Pengembangan Daerah] Provinsi Sulawesi Selatan.

Rahim, A. Rahman. (2011). Nilai-nilai utama kebudayaan Bugis. Ombak.

Rahim, Abdul Rahmam. (1984). Nilai-nilai utama kebudayaan Bugis [PhD Thesis]. Universitas Hasanuddin.

SAV PUSKAT. (2018). TRADISI LISAN_18_Karaeng Pattingalloang, Intelektual Abad ke-17 dari Makassar. https://www.youtube.com/watch?v=Xog WrOO30zc\&t=223s

Sewang, A. M. (2005). Islamisasi Kerajaan Gowa: Abad XVI sampai abad XVII. Yayasan Obor Indonesia.

Tamburaka, R. E. (1999). Pengantar Ilmu Sejarah, Teori Filsafat Sejarah, Sejarah Filsafat dan Iptek. Penerbit Rineka Cipta. 
Phinisi Integration Review. Vol 4(1) Februari 2021

Tika, Z. (2007). Karaeng Pattingalloang. Pustaka Refleksi.

Tobing, P. O. L. (1977). Hukum pelayaran dan perdagangan amanna gappa. Yayasan Kebudayaan Sulawesi Selatan.

Wolhoff, G. J. (n.d.). Abdurrahim.(1959) Sedjarah Goa. Ujung Pandang: Jajasan Kebudajaan Sulawesi Selatan Dan Tenggara. 